\title{
Cystathionine Promotes the Proliferation of Human Astrocytoma U373 Cells
}

\author{
HALINA JURKOWSKA and MARIA WRÓBEL \\ Chair of Medical Biochemistry, Jagiellonian University Medical College, Krakow, Poland
}

\begin{abstract}
Background/Aim: In certain cancers, accumulation of cystathionine has been observed. The present study investigated the effect of cystathionine on astrocytoma (U373) cell proliferation, the activity of $\gamma$-cystathionase $(\mathrm{CTH})$ and changes in thiols levels. Materials and Methods: The methods used in the study included cytotoxicity assay, crystal violet staining method, CTH activity assay and reverse phase-high performance liquid chromatography (RP-HPLC). Results: The addition of cystathionine to the culture medium resulted in an increase of cystathionine level in U373 cells after $24 \mathrm{~h}$ of culture. Reduction of intracellular cystathionine level after 48 and $72 \mathrm{~h}$ of culture was associated with increased L-cysteine and L-cystine levels and stimulation of cell proliferation. Interestingly, a decrease in intracellular L-cysteine and L-cystine levels during the first hours of culture was observed. Conclusion: Elevated levels of cystathionine resulted in increased U373 cell proliferation by increasing the L-cysteine levels and GSH/GSSG ratio (especially after $72 \mathrm{~h}$ of the culture), but not with a simultaneous increase in the levels of total glutathione.
\end{abstract}

Cystathionine is known as an intermediary metabolite in L-cysteine synthesis from methionine through the transsulfuration pathway. Endogenous synthesis of cystathionine, a sulfur-containing metabolite, is catalyzed by cystathionine $\beta$ synthase (CBS) via $\beta$-replacement reaction in which serine condenses with homocysteine in a pyridoxal-5'phosphatedependent manner. Cystathionine is subsequently converted to L-cysteine, $\alpha$-ketobutyrate and ammonia by the action of cystathionine $\gamma$-lyase (CTH) (Figure 1). L-cysteine is catabolized by desulfuration pathways (generating sulfane sulfur-containing compounds and $\mathrm{H}_{2} \mathrm{~S}$ ) and oxidative pathways (production of taurine and sulfate) and is used for glutathione and proteins

Correspondence to: Halina Jurkowska, Chair of Medical Biochemistry, Jagiellonian University Medical College, 7 Kopernika St., 31-034 Kraków, Poland. Tel: +48 124247229, e-mail: halina.jurkowska@ uj.edu.pl

Key Words: Cystathionine, brain cancer cells, thiols, sulfurtransferases, hydrogen sulfide. synthesis. Under physiological conditions, L-cysteine can substitute for serine, and the $\beta$-replacement of the sulfhydryl group of L-cysteine with homocysteine also results in cystathionine formation with release of $\mathrm{H}_{2} \mathrm{~S}$ (Figure 1) (1-3).

Cystathionine exerts anti-inflammatory (4) and antiapoptotic effects (5-8), is involved in eliminating superoxide radicals (9-11) and plays a role in liver protection against endoplasmic reticulum stress-induced injury $(6,12)$.

Cystathionine is a recently discovered substrate of cystine/glutamate transporter (system $\mathrm{xc}^{-}$) and may play an important role in regulating extracellular glutamate homeostasis in the brain (13). It is uncertain whether cystathionine serves as a direct precursor of L-cysteine for glutathione or whether it may replace incoming L-cystine at the level of the $\mathrm{xc}^{-}$exchanger. It is also uncertain whether cytosolic cystathionine itself is derived primarily from methionine by the transsulfuration pathway or if it enters the cells in place of L-cystine via the exchanger (14). The $\mathrm{xc}^{-}$ system plays significant roles in the growth and proliferation of cancer cells (15).

Massive accumulation of cystathionine and subsequent cystathioninuria have been observed as frequent and highly specific markers of neuroblastoma (16-19). Sen et al. (5) reported that cystathionine was selectively enriched in the breast cancer tissues as compared with undetectable levels in the normal breast tissues (5). Higher serum cystathionine as well as homocysteine and L-cysteine concentrations are also risk factors for metastatic prostate cancer progression and could serve as pre-surgical markers for aggressive disease (20). Wróbel et al. (21) reported that an average cystathionine level in higher grade human gliomas (II/III, III/IV and IV) was higher in comparison to low grade gliomas (II).

The purpose of the research undertaken in this study was to clarify whether the increase in cystathionine levels in cancer cells would affect their proliferation.

\section{Materials and Methods}

Sources of chemicals. D,L-Cystathionine, bathophenanthrolinedisulfonic acid (BPDS), 2,4-dinitrofluorobenzene (DNFB), acetonitrile, reduced nicotinamide adenine dinucleotide (NADH), lactate 
dehydrogenase (LDH), pyridoxal phosphate (PLP), Folin-Ciocialteau reagent, trypsin, Dulbecco's Modified Eagle Medium (DMEM), and crystal violet ( $\mathrm{N}$-hexamethylpararosaniline) were obtained from Sigma-Aldrich Corp. (St. Louis, MO, USA). Fetal bovine serum and penicillin/streptomycin were obtained from GIBCO Laboratories (Grand Island, NY, USA). Trifluoroacetic acid (TFA) and 2mercaptoethanol were obtained from Flucka Chemie GmbH. Nemethyl-L-lysine was purchased from Bachem (Bubendorf, Switzerland). All other chemicals were of reagent grade and purchased from common commercial suppliers.

Cell culture. Human astrocytoma U373 cells (ECACC, UK) were grown in DMEM supplemented with $10 \%$ fetal bovine serum (FBS), $2 \mathrm{mM} \mathrm{L}$-glutamine, and $1 \%$ penicillin-streptomycin (100 Units $/ \mathrm{ml}$ penicillin and $100 \mu \mathrm{g} / \mathrm{ml}$ streptomycin), at $37^{\circ} \mathrm{C}$ in humidified $95 \%$ air and $5 \% \mathrm{CO}_{2}$.

Cell homogenization. For determination of the level of reduced (GSH) and oxidized (GSSG) glutathione, L-cysteine, L-cystine and cystathionine, U373 cells were suspended in $0.1 \mathrm{ml} 10 \%$ perchloric acid/ $1 \mathrm{mM}$ BPDS. The sediment was separated by centrifugation at $1600 \mathrm{~g}$ for $10 \mathrm{~min}$, and the supernatant was saved at $-80^{\circ} \mathrm{C}$ until used for Reverse Phase-High Performance Liquid Chromatography (RP-HPLC) analyses.

For determination of CTH activity and protein level, U373 cells were suspended in $0.1 \mathrm{M}$ phosphate buffer $\mathrm{pH} 7.5$, in the ratio of $1 \times 10^{6}$ cells/ $0.04 \mathrm{ml}$ of the buffer, and sonicated $3 \times 5 \mathrm{sec}$ at $4^{\circ} \mathrm{C}$ (Bandelin Sonoplus GM 70). After centrifugation at $2800 \mathrm{~g}$ at $4^{\circ} \mathrm{C}$ for $10 \mathrm{~min}$, the supernatant was used for analysis.

Determination of cell viability. The effect of cystathionine on cell viability was assessed by measuring the leakage of lactate dehydrogenase (LDH) from dead or dying cells using a Cytotoxicity Detection Kit (Roche Applied Science, Penzberg, Germany) as described previously (22). The $0.25,0.5$ and $1 \mathrm{mM}$ concentrations of cystathionine that yielded LDH leakage of less than $5 \%$ were used for the experiments.

Cell proliferation. The U373 cells were seeded on 96-well plates at a concentration of $2 \times 10^{3}$ cells/well in DMEM supplemented as reported above. Following $24 \mathrm{~h}$ incubation, the culture medium was replaced with $100 \mu \mathrm{l}$ of culture medium (as a control) or $100 \mu \mathrm{l}$ of medium containing $0.25,0.5$ or $1 \mathrm{mM}$ cystathionine and the plates were cultured for 24, 48 and $72 \mathrm{~h}$. Cell proliferation was examined using the modified crystal violet staining method (23). The absorbance was measured using an Epoch Microplate Spectrophotometer (BioTek Instruments, Inc., Winooski, VT, USA).

CTH assay. CTH activity was determined according to Matsuo and Greenberg (24) as modified by Czubak et al. (25). The enzyme activity is expressed as nmoles of $\alpha$-ketobutyrate formed during 1 min incubation at $37^{\circ} \mathrm{C}$ per $1 \mathrm{mg}$ of protein. Protein concentration in the homogenates was determined by Lowry (26) method.

RP-HPLC analysis. The levels of non-protein thiols (L-cysteine, L-cystine, GSH and GSSG) and cystathionine were determined by the method of Dominick et al. (27), with some modification as described by Bronowicka-Adamska et al. (28).

Statistical analysis. All the experiments were repeated at least three times. Data are expressed as the means \pm standard deviation (SD).

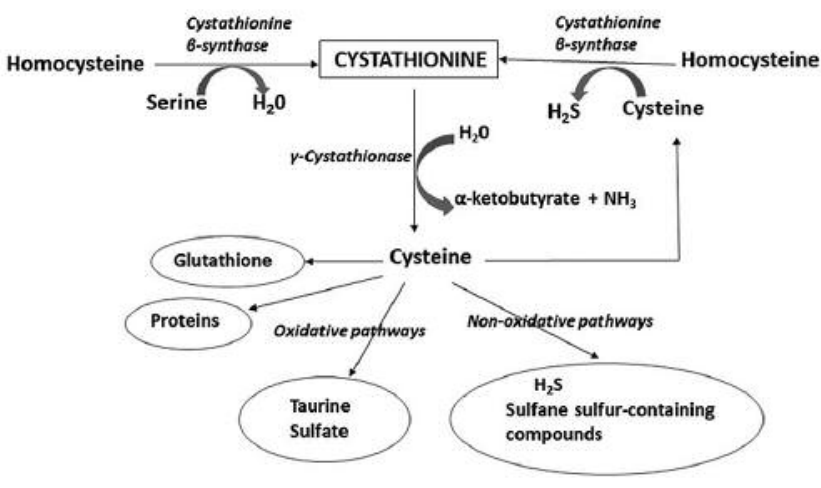

Figure 1. Metabolic pathways involved in cystathionine synthesis and catabolism.

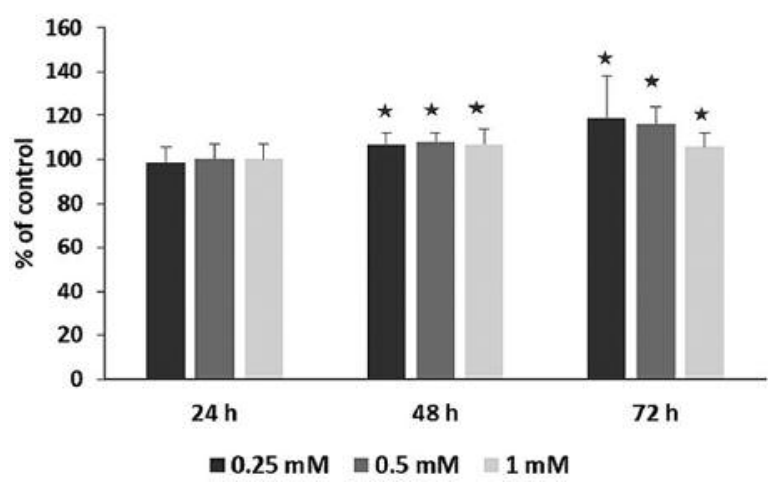

Figure 2. The effect of cystathionine on the proliferation of the U373 cells. The U373 cells were incubated for 24,48 and $72 \mathrm{~h}$ at various concentrations $(0.25,0.5,1 \mathrm{mM})$ of cystathionine. Cell proliferation was analyzed by the crystal violet assay. The data presented in the Figure are the mean $\pm S D$ of four independent experiments. ${ }^{*} p<0.05$ (Student's $t$-test) was considered statistically significant as compared with the nontreated controls.

Statistical analyses were performed using the Student's $t$-test. Differences were considered significant at $* p<0.05$.

\section{Results}

Effect of cystathionine on the proliferation of human astrocytoma U373 cell line. The U373 cells were cultured in the presence of various concentrations of cystathionine within 24, 48 and $72 \mathrm{~h}$, and subsequently, the crystal violet method was used for studying the cell proliferation. As shown in Figure 2, the proliferation of cystathionine-treated cells increased after 48 and $72 \mathrm{~h}$ of the culture. In the presence of $0.25,0.5$, and $1 \mathrm{mM}$ cystathionine, the U373 cell proliferation was increased respectively about $7 \%, 6 \%$ and $7 \%$ (after $48 \mathrm{~h}$ of the culture), and about 19\%, 16\%, and 6\% (after $72 \mathrm{~h}$ of the culture). Cystathionine did not affect the proliferation of U373 cells after 24 h treatment. 


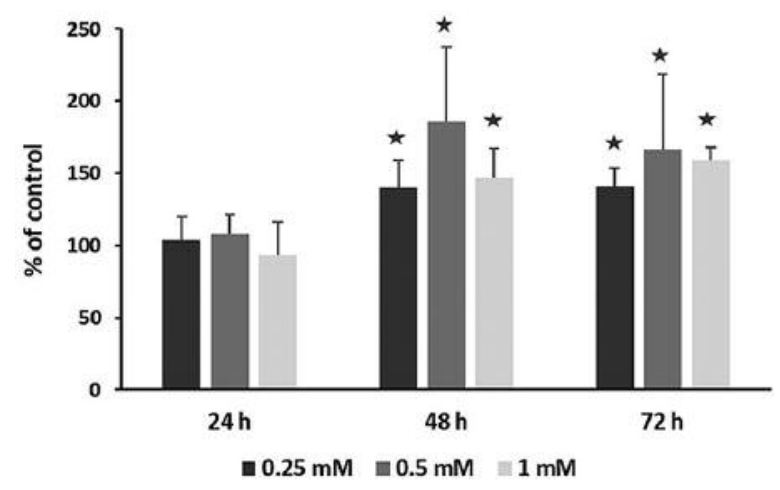

Figure 3. Cystathionine effect on $\gamma$-cystathionase activity in the U373 cells. The cells were treated with various concentrations of cystathionine $(0.25,0.5,1 \mathrm{mM})$ for 24,48 and $72 \mathrm{~h}$. Every value represents the mean $\pm S D$ of four independent experiments; * $p<0.05$ (Student's $t$-test). In the U373 cells, $\gamma$-cystathionase activity determined after 24,48 and 72 $h$ of the culture equaled, respectively, 398 $\pm 52,437 \pm 128$, and $373 \pm 156$ nmole $x$ mg protein-1 $x$ min-1 (control values).

Effect of cystathionine on $\gamma$-cystathionase activity in the human astrocytoma U373 cell line. The results presented in Figure 3 show changes in $\gamma$-cystathionase activity in the U373 cells in the presence of cystathionine $(0.25,0.5$, and $1 \mathrm{mM})$ during the culture. A significantly increased activity of CTH was observed in the U373 cells cultured for 48 and $72 \mathrm{~h}$ with cystathionine as compared to the control cells. For $0.25,0.5$, and $1 \mathrm{mM}$ cystathionine, CTH activity was increased by about $40 \%, 86 \%$, $47 \%$ after $48 \mathrm{~h}$ of cystathionine treatment, and by about $41 \%$, $66 \%, 59 \%$ after $72 \mathrm{~h}$, respectively.

Effect of cystathionine on the intracellular level of cystathionine, L-cysteine, L-cystine, GSH/GSSG ratio and total glutathione in the human astrocytoma U373 cell line. The RPHPLC method was used for the determination of cystathionine, L-cysteine, and L-cystine levels in the U373 cells. As compared to the cells cultured in DMEM without cystathionine, the addition of cystathionine $(0.25 \mathrm{mM}, 0.5 \mathrm{mM}$, $1 \mathrm{mM}$ ) resulted in the increase of the intracellular cystathionine levels in a concentration-dependent manner (Figure 4). The levels of cystathionine detected after $24 \mathrm{~h}$ were higher than after $48 \mathrm{~h}$ and $72 \mathrm{~h}$. As illustrated in Figure 5, during the first $24 \mathrm{~h}$ of the culture, L-cysteine and L-cystine levels in the U373 cells were significantly decreased in the presence of $0.5 \mathrm{mM}$ and $1 \mathrm{mM}$ cystathionine compared to the untreated cells (reduction of L-cysteine about 10-65\%; reduction of $\mathrm{L}$ cystine about $15-40 \%$ ). However, in the U373 cells treated with $0.5 \mathrm{mM}$ and $1 \mathrm{mM}$ cystathionine for $48 \mathrm{~h}$ and $72 \mathrm{~h}$, there was a time-dependent decrease in intracellular cystathionine levels (Figure 4), associated with increased L-cysteine and Lcystine levels (Figure 5). The GSH/GSSG ratio was increased in the presence of cystathionine in a time-dependent manner

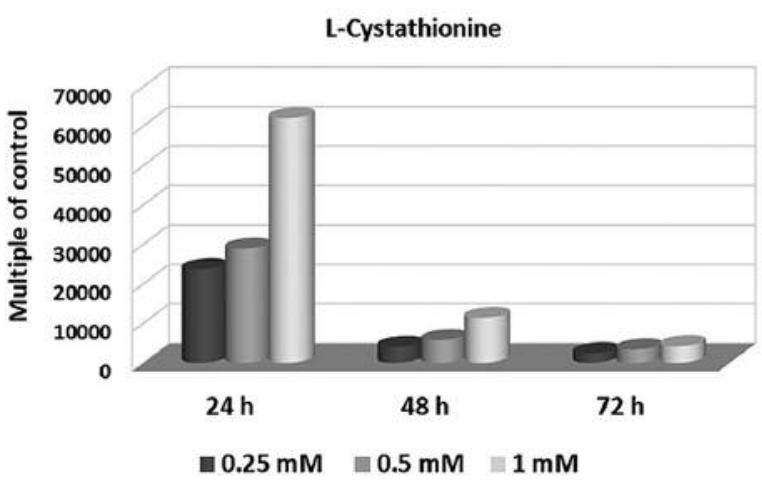

Figure 4. Cystathionine effect on the intracellular level of cystathionine in the U373 cells. The cells were incubated for 24,48 and $72 \mathrm{~h}$ in the presence of various concentrations of cystathionine $(0.25,0.5,1 \mathrm{mM})$. Every value represents the mean $\pm S D$ of three-four independent experiments. The intracellular level of cystathionine determined in the control U373 cells equaled to $0.41 \pm 0.21$ nmole $110^{6}$ cells.

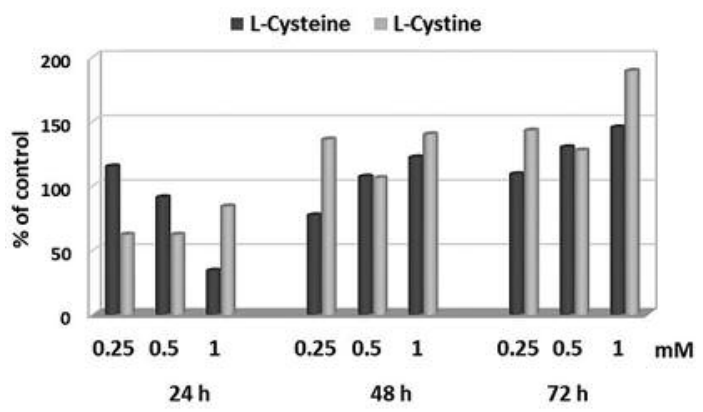

Figure 5. Cystathionine effect on the intracellular level of L-cysteine and L-cystine in the U373 cells. The cells were incubated for 24, 48 and $72 h$ in the presence of various concentrations of cystathionine $(0.25$ $\mathrm{mM}, 0.5 \mathrm{mM}, 1 \mathrm{mM})$. Every value represents the mean $\pm S D$ of three-four independent experiments. The intracellular level of L-cysteine and $L$ cystine determined in the control U373 cells equaled, respectively, $0.32 \pm 0.04$, and $2.51 \pm 0.96$ nmole $110^{6}$ cells.

(Figure 6A), however the level of total glutathione was unchanged (Figure 6B).

\section{Discussion}

The results of this study demonstrated that cystathionine promotes the proliferation of the human astrocytoma U373 cells in a time dependent-manner (Figure 2) and was associated with increased intracellular L-cysteine and Lcysteine levels (Figure 5) and GSH/GSSG ratio (Figure 6A). Interestingly, lack of simultaneous increase in the total glutathione level in the cystathionine-treated U373 cells (Figure 6B) suggests that cystathionine as a substrate of 

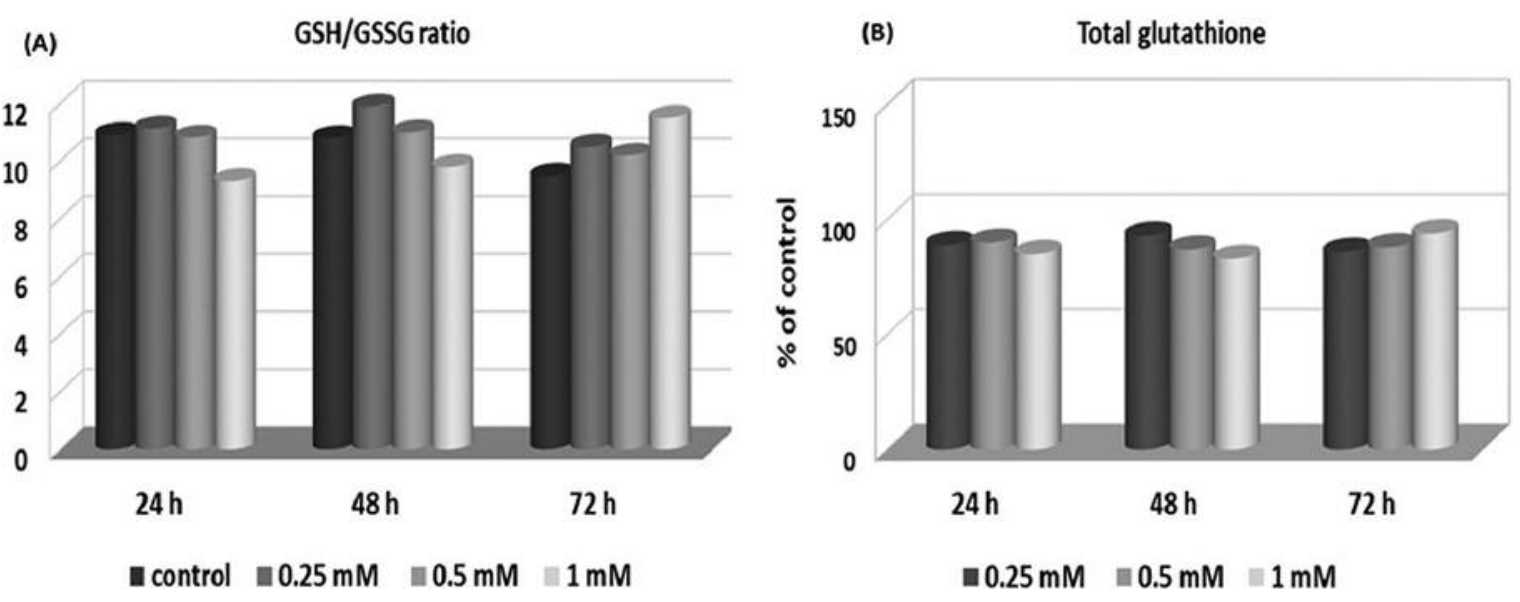

Figure 6. Cystathionine effect on the GSH/GSSG ratio (A) and the total glutathione (B) in U373 cells. The cells were incubated for 24,48 and $72 \mathrm{~h}$ in the presence of various concentrations of cystathionine $(0.25,0.5,1 \mathrm{mM})$. Every value represents the mean $\pm S D$ of three-four independent experiments.

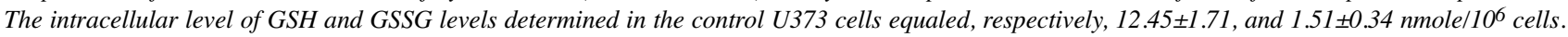

cystine/glutamate transporter (13) can compete with cystine for this transporter, also affecting the level of glutamate and consequently limiting the synthesis of glutathione. It was shown (29) that L-cysteine has a potential to stimulate proliferation and increase differentiation of the neural stem cells to neurons and astroglia. L-cysteine-induced proliferation was associated with the phosphorylation of extracellular signal-regulated kinases $1 / 2$ (ERK $1 / 2)$ and with altered expression of differentiation-related genes. L-cysteine can enhance proliferation and differentiation of the neural stem cells via the cystathionine $\beta$-synthase/ $\mathrm{H}_{2} \mathrm{~S}$ pathway (29). $\mathrm{H}_{2} \mathrm{~S}$ can also be generated from L-cysteine and L-cystine via various $\gamma$-cystathionase catalyzed reactions (30). Exogenous L-cysteine and L-cystine also promoted proliferation of the human colon cancer cells (31). Other reports showed that exogenous cystathionine protected macrophages against apoptosis induced by oxidized low-density lipoprotein (oxLDL) (7) and can inhibit apoptosis induced by tunicamycin (the endoplasmic reticulum stress inducing agent) in the human embryonic kidney cells (6). Sen et al. (5) reported that cystathionine protected the human breast cancer cells against excess reactive oxygen species and doxorubicin-induced apoptosis. Cystathionine inhibited mitochondria-mediated apoptosis via increasing mitochondrial membrane potential, inhibiting MPTP (Mitochondrial permeability transition pore complex) opening, suppressing cytochrome $\mathrm{c}$ release from the mitochondria into the cytoplasm, as well as downregulating caspase-9 activities and caspase-3 protein expression $(5,7)$.

It was also observed that the addition of cystathionine to the culture medium resulted in an increase in the intracellular cystathionine levels in a concentration-dependent manner (Figure 4), which confirmed its transport through the cell membrane. The highest level of cystathionine in the U373 cells was detected after $24 \mathrm{~h}$ of culture and then it gradually decreased after 48 and $72 \mathrm{~h}$ (Figure 4). Our previous results showed (32) that the activity of $\gamma$-cystathionase (CTH) in the U373 cells was low - about 0.4 nmole $\times \mathrm{mg}_{\text {protein }}{ }^{-1} \times \mathrm{min}^{-1}$. Addition of cystathionine resulted in an increase in the CTH activity after 48 and $72 \mathrm{~h}$ of treatment (Figure 3), and as a consequence, the level of L-cysteine in the cells was also elevated after 48 and $72 \mathrm{~h}$ (Figure 5). Interestingly, during the first $24 \mathrm{~h}$ of treatment, a high level of cystathionine in the U373 cells (Figure 4) was associated with the reduction of the intracellular L-cysteine and L-cystine levels (Figure 5). This suggests that cystathionine inhibits L-cysteine uptake in the U373 cells at the beginning of the culture when the cystathionine concentration in the medium is the highest. Kobayashi et al. (13) reported that in embryonic fibroblasts derived from wild-type embryos, L-cysteine uptake was significantly inhibited by cystathionine in a concentrationdependent manner. Kim et al. (33) showed that L-cystine uptake by the TcyABC transporter was also strongly inhibited by cystathionine in Streptococcus mutans.

In view of the fact that cystathionine promotes proliferation of U373 cells, the idea of using selective cystathionine $\beta$-synthase inhibitors, such as the natural biflavonoid compound sikokianin C, a recently described inhibitor (34), for inhibiting the proliferation of human brain cancer cells seems promising.

\section{Conflicts of Interest}

The Authors declare no conflicts of interest.

\section{Acknowledgements}

This work was supported by a Grant from the National Committee for Scientific Research No. K/ZDS/005887. 


\section{References}

1 Stipanuk $\mathrm{MH}$ and Ueki I: Dealing with methionine/ homocysteine sulfur: cysteine metabolism to taurine and inorganic sulfur. J Inherit Metab Dis 34: 17-32, 2011.

2 McBean GJ: The transsulfuration pathway: a source of cysteine for glutathione in astrocytes. Amino Acids 42: 199-205, 2012.

3 Shefa U, Kim MS, Jeong NY and Jung J: Antioxidant and cellsignaling functions of hydrogen sulfide in the central nervous system. Oxid Med Cell Longev 2018: 1873962, 2018.

4 Zhu M, Du J, Liu AD, Holmberg L, Chen SY, Bu D, Tang C and Jin H: L-cystathionine inhibits oxidized low density lipoproteininduced THP-1-derived macrophage inflammatory cytokine monocyte chemoattractant protein-1 generation via the NF-kB pathway. Sci Rep 5: 10453, 2015.

5 Sen S, Kawahara B, Mahata SK, Tsai R, Yoon A, Hwang L, HuMoore K, Villanueva C, Vajihuddin A, Parameshwar P, You M, Bhaskar DL, Gomez O, Faull KF, Farias-Eisner $\mathrm{R}$ and Chaudhuri G: Cystathionine: A novel oncometabolite in human breast cancer. Arch Biochem Biophys 604: 95-102, 2016.

6 Maclean KN, Greiner LS, Evans JR, Sood SK, Lhotak S, Markham NE, Stabler SP, Allen RH, Austin RC, Balasubramaniam $\mathrm{V}$ and Jiang $\mathrm{H}$ : Cystathionine protects against endoplasmic reticulum stress-induced lipid accumulation, tissue injury, and apoptotic cell death. J Biol Chem 287: 31994-32005, 2012.

7 Zhu M, Du J, Chen S, Dong Liu A, Holmberg L, Chen Y, Zhang $\mathrm{C}$, Tang $\mathrm{C}$ and Jin $\mathrm{H}$ : L-Cystathionine inhibits the mitochondriamediated macrophage apoptosis induced by oxidized low density lipoprotein. Int J Mol Sci 15: 23059-23073, 2014.

8 Ghibelli L, Fanelli C, Rotilio G, Lafavia E, Coppola S, Colussi C, Civitareale P and Ciriolo MR: Rescue of cells from apoptosis by inhibition of active GSH extrusion. FASEB J 12: 479-486, 1998.

9 Kouichirou W, Yoshinori K, Kentaro N and Tadao I: Effect of cystathionine as a scavenger of superoxide generated from human leukocytes or derived from xanthine oxidase in vitro. Eur J Pharmacol 296: 335-340, 1996.

10 Zhang J, Sugahara K, Sagara Y, Fontana M, Duprè S and Kodama $\mathrm{H}$ : Effect of cystathionine ketimine on the stimulus coupled responses of neutrophils and their modulation by various protein kinase inhibitors. Biochem Biophys Res Commun 218: 371-376, 1996.

11 Kodama H, Zhang J and Sugahara K: Novel priming compounds of cystathionine metabolites on superoxide generation in human neutrophils. Biochem Biophys Res Commun 269: 297-301, 2000.

12 Kitamura Y, Kamisaki Y and Itoh T: Hepatoprotective effects of cystathionine against acetaminophen-induced necrosis. J Pharmacol Exp Ther 250: 667-671, 1989.

13 Kobayashi S, Sato M, Kasakoshi T, Tsutsui T, Sugimoto M, Osaki M, Okada F, Igarashi K, Hiratake J, Homma T, Conrad M, Fujii J, Soga T, Bannai S and Sato H: Cystathionine is a novel substrate of cystine/glutamate transporter: implications for immune function. J Biol Chem 290: 8778-8788, 2015.

$14 \mathrm{McBean}$ GJ: Cysteine, glutathione, and thiol redox balance in astrocytes. Antioxidants (Basel) 6: pii: E62, 2017.

15 Paul BD, Sbodio JI and Snyder SH: Cysteine metabolism in neuronal redox homeostasis. TIPS 1508: 1-12, 2018.

16 Gjessing LR: Studies of functional neural tumors isolation and identification of urinary cystathionine. Scand J Clin Lab Invest 15: 601-602, 1963.

17 Geiser CF and Efron ML: Cystathioninuria in patients with neuroblastoma or ganglioneuroblastoma. Its correlation to vanilmandelic acid excretion and its value in diagnosis and therapy. Cancer 22: 856-860, 1968.

18 Helson L, Fleisher M, Bethune V, Murphy ML and Schwartz MK: Urinary cystathionine, catecholamine, and metabolites in patients with neuroblastoma. Clin Chem 18: 613-615, 1972.

19 Klein CE, Roberts B, Holcenberg J and Glode LM: Cystathionine metabolism in neuroblastoma. Cancer 62: 291-298, 1988.

20 Stabler S, Koyama T, Zhao Z, Martinez-Ferrer M, Allen RH, Luka Z, Loukachevitch LV, Clark PE, Wagner C and Bhowmick NA: Serum methionine metabolites are risk factors for metastatic prostate cancer progression. PLoS One 6: e22486, 2011.

21 Wróbel M, Czubak J, Bronowicka-Adamska P, Jurkowska H, Adamek D and Papla B: Is development of high-grade gliomas sulfur-dependent? Molecules 19: 21350-21362, 2014.

22 Jurkowska H, Uchacz T, Roberts J and Wróbel M: Potential therapeutic advantage of ribose-cysteine in the inhibition of astrocytoma cell proliferation. Amino Acids 41: 131-139, 2011.

23 Gillies RJ, Didier N and Denton M: Determination of cell number in monolayer cultures. Anal Biochem 159: 109-113, 1986.

24 Matsuo Y and Greenberg DM: A crystalline enzyme that cleaves homoserine and cystathionine: I. Isolation procedure and some physiochemical properties. J Biol Chem 230: 545-560, 1958.

25 Czubak J, Wróbel M and Jurkowska H: Cystathionine $\gamma$-lyase (EC 4.4.1.1): An enzymatic assay of $\alpha$-ketobutyrate using lactate dehydrogenase. Acta Biol Crac Ser Zool 44: 113-117, 2002.

26 Lowry OH, Rosebrough NJ, Farr L and Randall RJ: Protein measurement with the folin phenol reagent. J Biol Chem 193: 265-275, 1951.

27 Dominick PK, Cassidy PB and Roberts JC: A new and versatile method for determination of thiolamines of biological importance. J Chromatogr B Biomed Sci Appl 761: 1-12, 2001.

28 Bronowicka-Adamska P, Zagajewski J, Czubak J and Wróbel M: RP-HPLC method for quantitative determination of cystathionine, cysteine and glutathione: An application for the study of the metabolism of cysteine in human brain. J Chromatogr B Analyt Technol Biomed Life Sci 879: 2005-2009, 2011.

29 Wang Z, Liu DX, Wang FW, Zhang Q, Du ZX, Zhan JM, Yuan $\mathrm{QH}$, Ling EA and Hao AJ: L-Cysteine promotes the proliferation and differentiation of neural stem cells via the $\mathrm{CBS} / \mathrm{H}_{2} \mathrm{~S}$ pathway. Neuroscience 237: 106-117, 2013.

30 Kolluru GK, Shen X, Bir SC and Kevil CG: Hydrogen sulfide chemical biology: Pathophysiological roles and detection. Nitric Oxide 35: 5-20, 2013.

31 Noda T, Iwakiri R, Fujimoto K, Rhoads CA and Aw TY: Exogenous cysteine and cysteine promote cell proliferation in CaCo-2 cells. Cell Prolif 35: 117-129, 2002.

32 Jurkowska H, Placha W, Nagahara N and Wróbel M: The expression and activity of cystathionine-c-lyase and 3-mercaptopyruvate sulfurtransferase in human neoplastic cell lines. Amino Acids 41: 151-158, 2011.

33 Kim J, Senadheera DB, Lévesque CM and Cvitkovitch DG: TcyR regulates L-cystine uptake via the TcyABC transporter in Streptococcus mutans. FEMS Microbiol Lett 328: 114-121, 2012.

34 Niu W, Chen F, Wang J, Qian J and Yan S: Antitumor effect of sikokianin $\mathrm{C}$, a selective cystathionine $\beta$-synthase inhibitor, against human colon cancer in vitro and in vivo. Med Chem Commun 9: 113-120, 2018.

Received March 28, 2018

Revised April 19, 2018

Accepted April 20, 2018 